\title{
CRAF mutations in lung cancer can be oncogenic and predict sensitivity to combined type II RAF and MEK inhibition
}

\author{
Amir Noeparast $\mathbb{B}^{1}$ - Philippe Giron ${ }^{1}$ - Alfiah Noor ${ }^{1}$ - Rajendra Bahadur Shahi $\mathbb{C}^{1}$ - Sylvia De Brakeleer ${ }^{1}$. \\ Carolien Eggermont ${ }^{1} \cdot$ Hugo Vandenplas ${ }^{1} \cdot$ Bram Boeckx $^{2,3} \cdot$ Diether Lambrechts $^{2,3} \cdot$ Jacques De Grève ${ }^{1}$. \\ Erik Teugels ${ }^{1}$
}

Received: 18 June 2018 / Revised: 4 April 2019 / Accepted: 28 April 2019 / Published online: 08 July 2019

(c) The Author(s) 2019. This article is published with open access

\begin{abstract}
Two out of 41 non-small cell lung cancer patients enrolled in a clinical study were found with a somatic CRAF mutation in their tumor, namely $\mathrm{CRAF}^{\mathrm{P} 261 \mathrm{~A}}$ and $\mathrm{CRAF}^{\mathrm{P} 207 \mathrm{~S}}$. To our knowledge, both mutations are novel in lung cancer and $\mathrm{CRAF}^{\mathrm{P} 261 \mathrm{~A}}$ has not been previously reported in cancer. Expression of CRAF ${ }^{\text {P261A }}$ in HEK293T cells and BEAS-2B lung epithelial cells led to increased ERK pathway activation in a dimer-dependent manner, accompanied with loss of CRAF phosphorylation at the negative regulatory $\mathrm{S} 259$ residue. Moreover, stable expression of $\mathrm{CRAF}^{\mathrm{P} 261 \mathrm{~A}}$ in mouse embryonic fibroblasts and BEAS2B cells led to anchorage-independent growth. Consistent with a previous report, we could not observe a gain-of-function with CRAF ${ }^{\mathrm{P} 207 \mathrm{~S}}$. Type II but not type I RAF inhibitors suppressed the $\mathrm{CRAF}^{\mathrm{P} 261 \mathrm{~A}}$-induced ERK pathway activity in BEAS2B cells, and combinatorial treatment with type II RAF inhibitors and a MEK inhibitor led to a stronger ERK pathway inhibition and growth arrest. Our findings suggest that the acquisition of a CRAF ${ }^{\mathrm{P} 261 \mathrm{~A}}$ mutation can provide oncogenic properties to cells, and that such cells are sensitive to combined MEK and type II RAF inhibitors. CRAF mutations should be diagnostically and therapeutically explored in lung and perhaps other cancers.
\end{abstract}

\section{Introduction}

The RAF kinase family, which consists of three isoforms, ARAF, BRAF, and CRAF (RAF1), transmit signal from

These authors contributed equally: Amir Noeparast, Philippe Giron

Supplementary information The online version of this article (https:// doi.org/10.1038/s41388-019-0866-7) contains supplementary material, which is available to authorized users.

Amir Noeparast

amir.noeparast@vub.be

$\triangle$ Jacques De Grève

jacques.degreve@uzbrussel.be

$\triangle$ Erik Teugels

eteugels@uzbrussel.be

1 Laboratory of Molecular Oncology and Department of Medical Oncology, Oncologisch Centrum, UZ Brussel, Vrije Universiteit Brussel, Brussels, Belgium

2 Vesalius Research Center, VIB, 3000 Leuven, Belgium

3 Laboratory of Translational Genetics, Department of Oncology KU Leuven, 3000 Leuven, Belgium
RAS to MEK along the RAS/RAF/MEK/ERK molecular pathway [1]. RAF kinase family members share three conserved regions (CR1-CR3) [1]. The kinase activity of CRAF is higher than ARAF but lower than BRAF [1,2]. BRAF and CRAF germline mutations have been previously described in rasopathies [2-4]. Somatic BRAF mutations have been detected in $\sim 8 \%$ of human tumors including nonsmall cell lung cancer (NSCLC) (5\%) and melanoma ( $50 \%)$, whereas CRAF mutations are very rarely reported in cancer $[1,3]$. With the emergence of genome-wide nextgeneration sequencing, somatic CRAF mutations in cancer appear to occur more frequently than previously considered [4-6]. We performed whole exome sequencing of 41 available paired tumor/matched normal tissue samples derived from a prospective cohort of "strictly non-smoking" or "formerly limited smoking" NSCLC patients and detected two CRAF mutations, namely $\mathrm{CRAF}^{\mathrm{P} 261 \mathrm{~A}}$ and $\mathrm{CRAF}^{\mathrm{P} 207 \mathrm{~S}}$ (manuscript in preparation). To our knowledge, these CRAF mutations have never been reported in lung cancer. One of these mutations, $\mathrm{CRAF}^{\mathrm{P} 261 \mathrm{~A}}$, is located in conserved region CR2 and has never been reported in human cancer. However, a CRAF ${ }^{\mathrm{P} 261 \mathrm{~A}}$ germline mutation was reported in Noonan syndrome (rasopathy) and its 
characterization revealed that it activates the ERK pathway at higher levels compared with $\mathrm{CRAF}^{\mathrm{WT}}$ [7].

Markedly, the 14-3-3 proteins can bind to the CR2 of CRAF, at the phosphorylated S259 (and with lower affinity at p-S233), thereby stabilizing the CRAF auto-inhibition state [1, 8-10]. CRAF mutations at CR2 can affect the 14-33-binding motif or its recognition by phosphatases, and thereby promoting CRAF kinase activation $[1,7,11]$.

The other mutation, $\mathrm{CRAF}^{\mathrm{P} 207 \mathrm{~S}}$, located at a nonconserved region between CR1 and CR2, was previously identified in a fibrosarcoma cell line and reported as incapable of activating the ERK pathway at higher levels than wild-type CRAF and its role as an oncogene remained undetermined [2].

Predicting the efficacy of RAF inhibitors in targeting mutated CRAF is still a challenge. A melanoma-derived oncogenic CRAF mutation $\left(\mathrm{CRAF}^{\mathrm{R} 391 \mathrm{~W}}\right)$, which signals as a dimer, is reported to be resistant to Vemurafenib (a type I RAF inhibitor) [12]. Of note, acquisition of mutations at S259 or adjacent residues of CRAF including P261 [13] has also been described as one of the resistance-conferring mechanisms to type I RAF inhibitor therapy in mutant $\mathrm{BRAF}^{\mathrm{V} 600 \mathrm{E}}$ melanomas [13]. In contrast, lung cancerderived mutations at S259 and S257 CRAF have been shown to predict sensitivity to Sorafenib, a type II RAF and multiple kinase inhibitor [6].

In the present work, we investigated the "actionability" of these lung cancer-derived CRAF mutations with ERK pathway inhibitors (RAF and MEK inhibitors) and further determined the comparative efficacy of two classes of RAF inhibitors in targeting these mutations.

\section{Results and discussion}

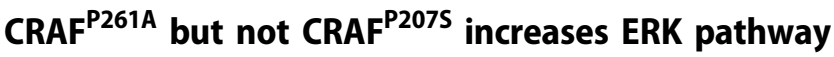 activity in a dimer-dependent manner}

To determine whether $\mathrm{CRAF}^{\mathrm{P} 261 \mathrm{~A}}$ and $\mathrm{CRAF}^{\mathrm{P} 207 \mathrm{~S}}$ mutations can induce ERK pathway activation at higher levels compared with the wild-type CRAF, we introduced CRAF $^{\text {P261A }}$ and CRAF $^{\mathrm{P} 207 \mathrm{~S}}$ mutations into the wild-type CRAF coding sequence by site-directed mutagenesis and transiently expressed the mutant CRAF recombinant proteins in HEK293T and BEAS-2B cells. As shown in Fig. 1a, b, the expression of $\mathrm{CRAF}^{\mathrm{P} 261 \mathrm{~A}}$ led to increased MEK and ERK activation in both HEK293T and BEAS-2B cellular models. The enhanced MEK and ERK activity induced by $\mathrm{CRAF}^{\mathrm{P} 261 \mathrm{~A}}$ was less pronounced in BEAS-2B cells, which could be explained by a lesser transfection efficiency of BEAS-2B cells as opposed to HEK293T cells. It was previously reported that phosphorylation of CRAF at S338 is crucial for its activation, linking it to cancer progression [14-16], whereas phosphorylation at residue S259 (a negative regulatory site adjacent to P261) is essential for CRAF auto-inhibition [10, 17]. In all tested conditions we observed that increased ERK pathway activity induced by CRAF $^{\mathrm{P} 261 \mathrm{~A}}$ was accompanied by a clear decline in S259-CRAF phosphorylation levels (Fig. 1a, b). In contrast, no marked increase in S338-CRAF phosphorylation levels was observed (Fig. 1a, b).

RAF targeting studies including a recent study by us have shown that monomer vs. dimer signaling of BRAF can determine its mode of response to RAF inhibition [5, 18-31]. However, whether $\mathrm{CRAF}^{\mathrm{P} 261 \mathrm{~A}}$ functions as a monomer or a dimer, and whether it predicts sensitivity to the ERK pathway inhibitors were yet to be uncovered. Therefore, we introduced the well-studied dimerization-disrupting $\mathrm{R} 401 \mathrm{H}$ mutation in $\mathrm{CRAF}^{\mathrm{P} 261 \mathrm{~A}}[12,25,31,32]$. We observed that $\mathrm{CRAF}^{\mathrm{P} 261 \mathrm{~A} / \mathrm{R} 401 \mathrm{H}}$ could no longer induce ERK pathway activation, indicating that CRAF $^{\text {P261A }}$ signals as a dimer and not as a monomer (Fig. 1c). This observation suggests that CRAF $^{\mathrm{P} 261 \mathrm{~A}}$ still requires dimerization to allow hyperactivation of the ERK pathway, following disruption of 143-3 proteins binding to its N-terminal binding motif, as indicated by loss of S259 phosphorylation. Similar findings have been reported for BRAF ${ }^{\mathrm{S} 365 \mathrm{~A}}$ (BRAF $^{\mathrm{S} 365}$ is homologous to $\mathrm{CRAF}^{\mathrm{S} 259}$ ), which is also impaired in 14-3-3 binding to the CR2 [33].

In contrast to $\mathrm{CRAF}^{\mathrm{P} 261 \mathrm{~A}}, \mathrm{CRAF}^{\mathrm{P} 207 \mathrm{~S}}$ did not induce MEK and ERK phosphorylation at higher levels compared with $\mathrm{CRAF}^{\mathrm{WT}}$ (Fig. 1a, b). We postulated that $\mathrm{CRAF}^{\mathrm{P} 207 \mathrm{~S}}$, like kinase-impaired BRAF mutants that allosterically activate their heterodimerization partner (CRAF), might function in co-operation with wild-type BRAF. Therefore, we overexpressed CRAF recombinant proteins in HEK293T cells together with BRAF $^{\mathrm{WT}}$. As shown in Fig. 1d, co-expression of BRAF together with CRAF $^{\text {P2075 }}$ did not lead to increased MEK and ERK activation when compared with $\mathrm{CRAF}^{\mathrm{WT}} / \mathrm{BRAF}$ co-transfectants (idem for CRAF $^{\text {P261A }}$ ).

\section{CRAF $^{\text {P261A }}$ transforms mouse embryonic fibroblasts and human lung epithelial cells}

To determine whether $\mathrm{CRAF}^{\mathrm{P} 207 \mathrm{~S}}$ and $\mathrm{CRAF}^{\mathrm{P} 261 \mathrm{~A}}$ mutations can induce anchorage-independent growth, a hallmark of carcinogenesis, we stably transduced lung epithelial cells (BEAS-2B) and mouse embryonic fibroblasts of two different origins (NIH3T3 [34] derived from Swiss 3T3 mice and another immortalized MEF [35] derived from C57BL/ $6 \mathrm{~J}$ mice, hereafter mentioned as MEF), with lentiviral vectors bearing recombinant wild-type and mutant forms of CRAF. The anchorage-independent growth was determined using a soft agar colony-formation assay, which is considered as a stringent test for malignant transformation. As 
Fig. $1 \mathrm{CRAF}^{\mathrm{P} 261 \mathrm{~A}}$ activates the ERK pathway in HEK293T and BEAS-2B cells, and signals as a dimer. HEK293T (a) or BEAS2B cells (b) cells were transiently transfected with a $\mathrm{CRAF}^{\mathrm{P} 261 \mathrm{~A}}, \mathrm{CRAF}^{\mathrm{P} 207 \mathrm{~S}}$, or $\mathrm{CRAF}^{\mathrm{WT}}$ expression vectors alone. The $\mathrm{CRAF}^{\mathrm{P} 261 \mathrm{~A}}$ mutation hyperactivates the ERK pathway. The prevention of CRAF dimerization (by $\mathrm{CRAF}^{\mathrm{R} 401 \mathrm{H}}$ ) abolishes CRAF $^{\text {P261A }}$ hyperactivation of the ERK pathway in HEK293T cells (c). Coexpression of CRAF ${ }^{\mathrm{WT}}$, CRAF $^{\mathrm{P} 261 \mathrm{~A}}$, or CRAF ${ }^{\mathrm{P} 207 \mathrm{~S}}$ with BRAF $^{\mathrm{WT}}$ (as previously described [22]) in HEK293T cells do not result in higher (or lower) ERK pathway activation compared with single transfections (d). Forty-eight hours post-transfection cells were lysed and subjected to western blotting analysis to detect the indicated proteins (a, b, c, d). EV stands for empty vector. Lipofectamine was added in the mock condition

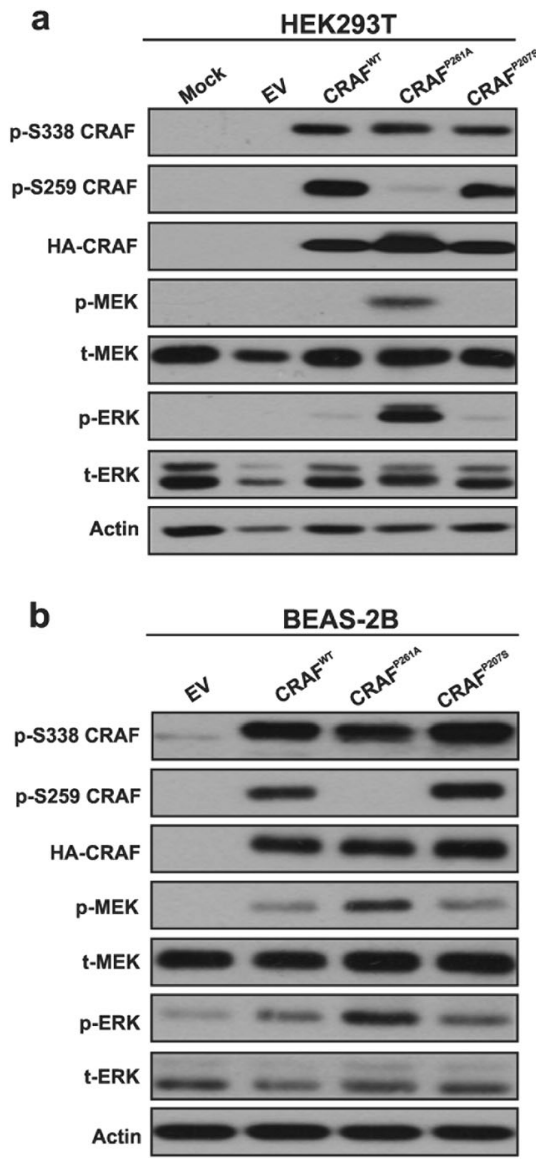

shown in Fig. 2a-c, the number of colonies formed after transducing BEAS-2B, NIH3T3, and MEF cells with $\mathrm{CRAF}^{\mathrm{P} 261 \mathrm{~A}}$ strongly increases when compared with $\mathrm{CRAF}^{\mathrm{WT}}$ transductions. We observed a 10.6-fold, 18.4-fold, and 25-fold increase in colony formation for respectively BEAS-2B, NIH3T3 (the least pronounced) and MEF stably transduced cells. Comparable results were not obtained when transducing cells with $\mathrm{CRAF}^{\mathrm{P} 207 \mathrm{~S}}$ (Fig. 2a, b). Indeed, $\mathrm{CRAF}^{\mathrm{P} 207 \mathrm{~S}}$ exhibited only a meagre transforming activity (Fig. 2a, b), which correlates with the observed lack of ERK pathway activation (Fig. 1a, b).

In addition, $\mathrm{CRAF}^{\mathrm{P} 261 \mathrm{~A}}$ not only generates more colonies but also clearly induces the formation of larger colonies (Fig. 2d-f, Supplementary Fig. S1d and S1e) compared with $\mathrm{CRAF}^{\mathrm{WT}}$. Interestingly, the capacity of $\mathrm{CRAF}^{\mathrm{P} 261 \mathrm{~A}}$ to form colonies in BEAS-2B was relatively high, as it was only four fold less than for the well-characterized $\mathrm{BRAF}^{\mathrm{V} 600 \mathrm{E}}$, which has been reported to rank among the highest ERK pathway activating BRAF mutants [22, 23, 36] (Supplementary Fig. S1a and S1e). We also tested $\mathrm{CRAF}^{\mathrm{S} 259 \mathrm{~A}}$ as a control, and consistent with two previous reports [6, 37] we observed that this variant induces increased anchorage-independent growth in lung epithelial and MEFs (Supplementary Fig. S1).

\section{CRAF $^{\text {P261A }}$-induced ERK pathway activation is suppressed by type II inhibitors, but paradoxically increased by type I inhibitors}

Several studies have suggested that ERK pathway activating cancer-derived CRAF mutations are oncogenic, but their response to RAF inhibitors is still uncertain [4, 6, 13]. In this study, we first tested three RAF inhibitors (Dabrafenib, LY3009120, and AZ628) at the clinically relevant dose of $1 \mu \mathrm{M}$ by measuring ERK pathway activity in BEAS-2B cells transiently expressing CRAF recombinant proteins. Dabrafenib is a type I RAF inhibitor (recently characterized as type 1.5 inhibitor [27]), which stabilizes the drug-bound RAF molecule in a DFG-in conformation [27]. AZ628 and LY3009120 are both type II RAF inhibitors and stabilize RAF in the DFG-out conformation [23, 26, 29]. Dabrafenib is Food and Drug Administration-approved for the treatment of V600E/K BRAF melanoma and has an affinity for CRAF as well [22, 38]; LY3009120 has been recently tested clinicaly (phase I study) in mutant BRAF and KRAS cancers (NCT02014116), and AZ628 is an experimental RAF inhibitor.

Dabrafenib treatment of $\mathrm{CRAF}^{\mathrm{WT}}$ expressing BEAS-2B cells whether in the absence or presence of BRAF led to 

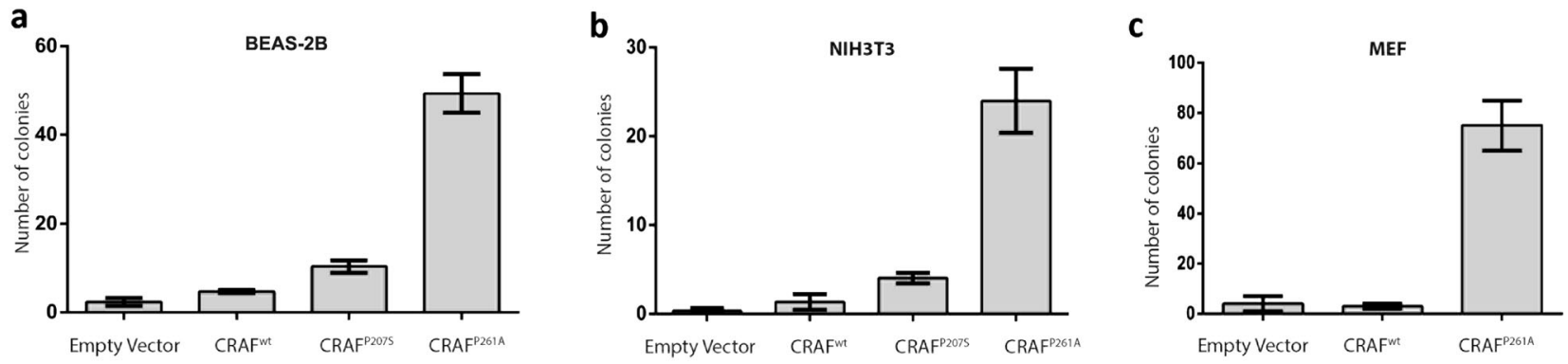

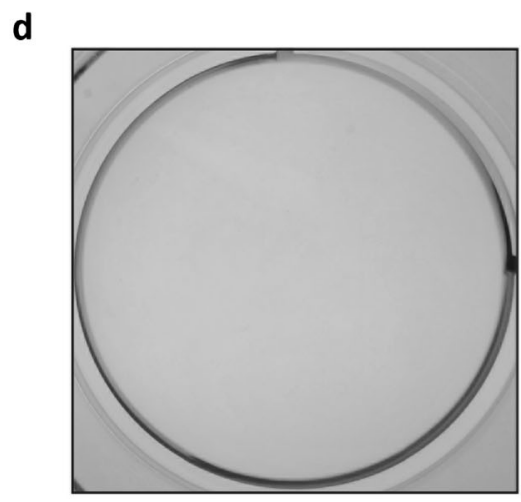

Empty Vector

e

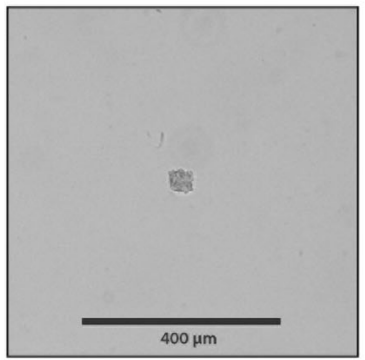

Empty Vector

Fig. 2 CRAF $^{\mathrm{P} 261 \mathrm{~A}}$ induces anchorage-independent growth. BEAS-2B (a), NIH3T3 (b), and MEF (c) cells were stably transduced with empty vector, $\mathrm{CRAF}^{\mathrm{WT}}, \mathrm{CRAF}^{\mathrm{P} 207 \mathrm{~S}}$ (only in BEAS-2B and NIH3T3), or $\mathrm{CRAF}^{\mathrm{P} 261 \mathrm{~A}}$ as indicated $(\mathbf{a}-\mathbf{c})$. Total number of colonies per well were counted (representative experiment) after $16(\mathbf{c})$ or $18(\mathbf{a}, \mathbf{b})$ days in culture. The experiments were performed with three biological repeats and were represented as a bar chart (means \pm SEM). d Representative

paradoxical ERK pathway activation compared with dimethyl sulfoxide (DMSO) (vehicle) treatment (Fig. 3a and Supplementary Fig. S2). As previously shown $[1,21,25,32,39]$, when a type I RAF inhibitor (Dabrafenib) binds to one $\mathrm{CRAF}^{\mathrm{WT}}$ homodimer partner, the other dimer partner is transactivated, resulting in paradoxical ERK activation. Notably, a similar phenomenon was observed upon Dabrafenib treatment of cells expressing either CRAF ${ }^{\mathrm{P} 261 \mathrm{~A}}$ or CRAF ${ }^{\mathrm{P} 207 \mathrm{~S}}$ (Fig. 3a and Supplementary Fig. S1). In contrast, both AZ628 and LY3009120 suppressed ERK activity in $\mathrm{CRAF}^{\mathrm{P} 261 \mathrm{~A}}$ - and $\mathrm{CRAF}^{\mathrm{P} 207 \mathrm{~S}}$-expressing cells in the presence or absence of BRAF and did not induce ERK paradoxical activity in
$\mathrm{CRAF}^{\mathrm{WT}}$-expressing cells (Fig. 3a and Supplementary Fig. S2). The differential effect of type I vs. type II RAF inhibition can be explained by our observation that $\mathrm{CRAF}^{\mathrm{P} 261 \mathrm{~A}}$ relies on dimerization for downstream signaling. Indeed, the abolishment of ERK pathway signaling observed when $\mathrm{CRAF}^{\mathrm{P} 261 \mathrm{~A}}$ mutant proteins were rendered unable to dimerize suggests that only inhibitors that concomitantly block the kinase activity of both RAF dimer partners (=type II inhibitors) can suppress CRAF $^{\text {P261A }}$-induced ERK pathway activation.

Interestingly, in $\mathrm{CRAF}^{\mathrm{P} 207 \mathrm{~S}}$ mono-transfectants, both AZ628 and LY3009120 induced a slight increase in p-MEK levels, which was not consistent with the observed decline 
a
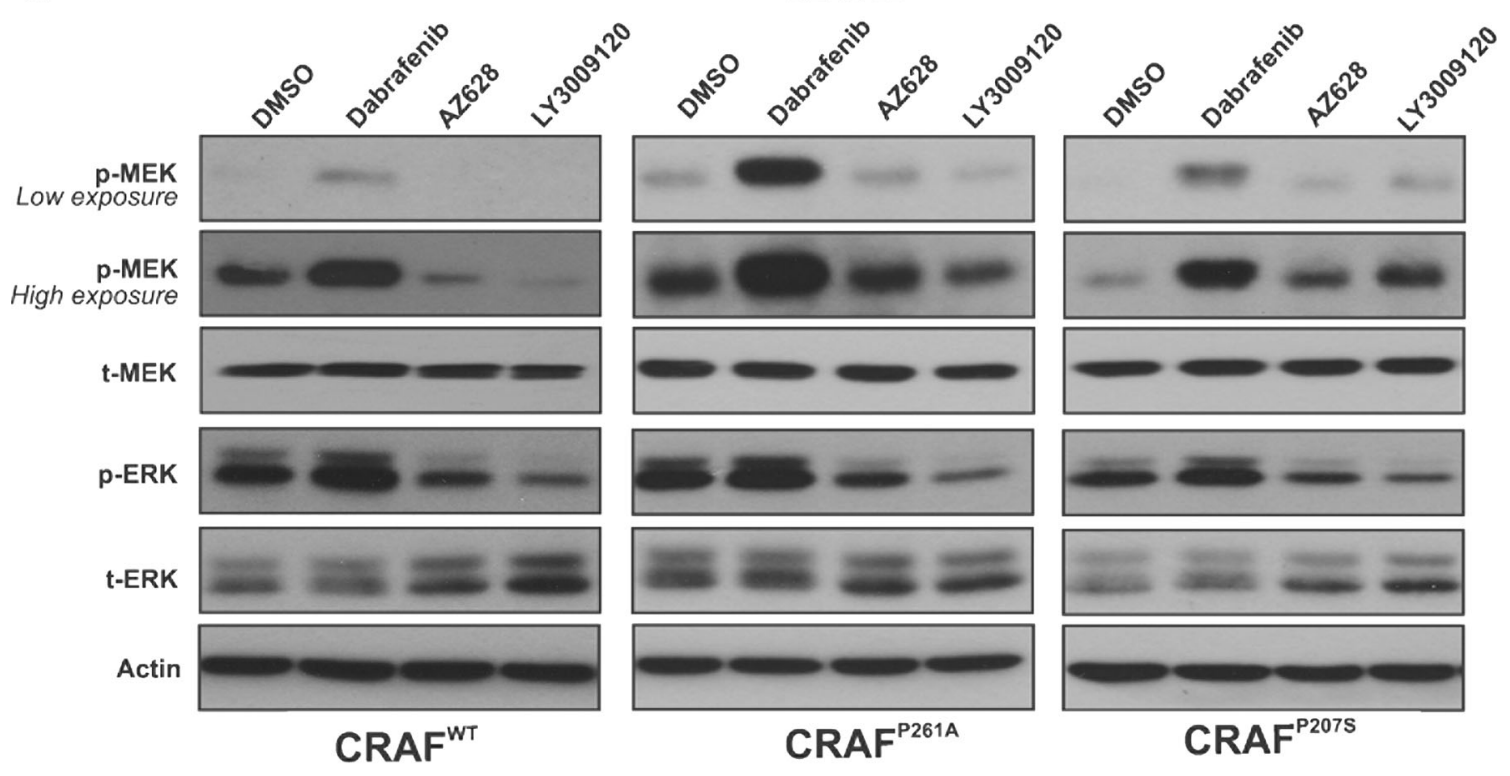

b

BEAS-2B

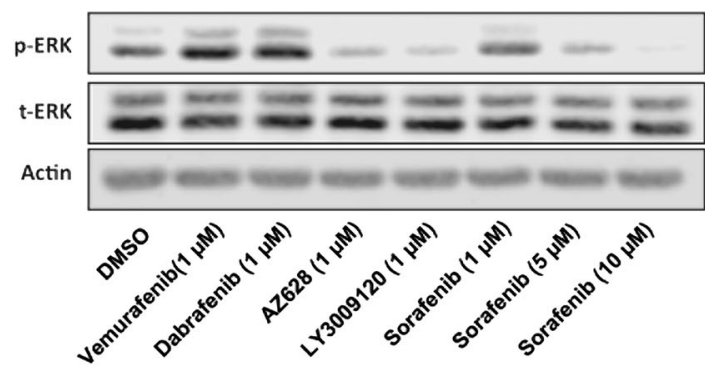

C
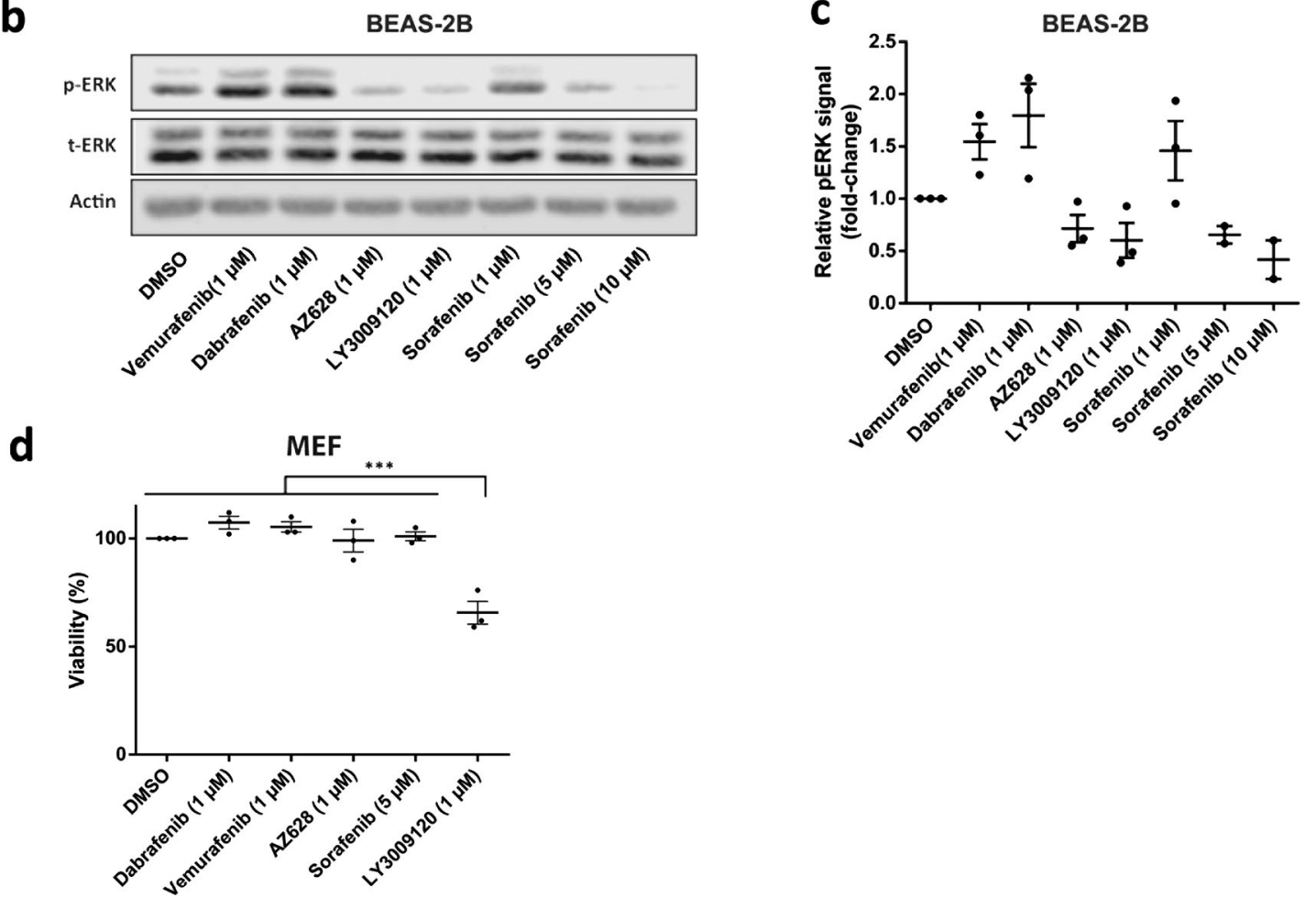

Fig. $3 \mathrm{CRAF}^{\mathrm{P} 261 \mathrm{~A}}$-induced ERK pathway activation is suppressed by type II RAF inhibitors. a BEAS-2B cells were transiently transfected with different CRAF expression vectors (wild type or mutant). Forty-eight hours post transfection, cells were treated for $2 \mathrm{~h}$ with DMSO, Dabrafenib $(1 \mu \mathrm{M})$, or AZ628 $(1 \mu \mathrm{M})$, or LY3009120 $(1 \mu \mathrm{M})$, then lysed and subjected to western blotting analysis to detect the indicated proteins. b, c BEAS-2B cells were transiently transfected with $\mathrm{CRAF}^{\mathrm{P} 261 \mathrm{~A}}$. Forty-eight hours post transfection, cells were treated for $2 \mathrm{~h}$ with DMSO, Vemurafenib, Dabrafenib, AZ628, LY3009120, or Sorafenib (drug concentrations are indicated). b Cells were lysed and subjected to western blotting analysis to detect the indicated proteins. c Graphical representation of the relative p-ERK signals (normalized to actin and DMSO group) based on at least two independent experiments as shown in b. Dots represent individual data points, lines represent the mean value \pm SEM. d MEF cells stably expressing $\mathrm{CRAF}^{\mathrm{P} 261 \mathrm{~A}}$ were treated with DMSO, Vemurafenib, Dabrafenib, AZ628, LY3009120, or Sorafenib (all at $1 \mu \mathrm{M}$ but Sorafenib at $5 \mu \mathrm{M}$ ) for a duration of $72 \mathrm{~h}$. Cell viability was determined using CellTiter-Glo. The dots represent the means of the independent experiments, the horizontal lines with error bars represent the mean \pm SEM of three independent experiments each performed at least in triplicate. Statistical significance was indicated by $* * *$ and represents a $p$-value $<0.001$ 

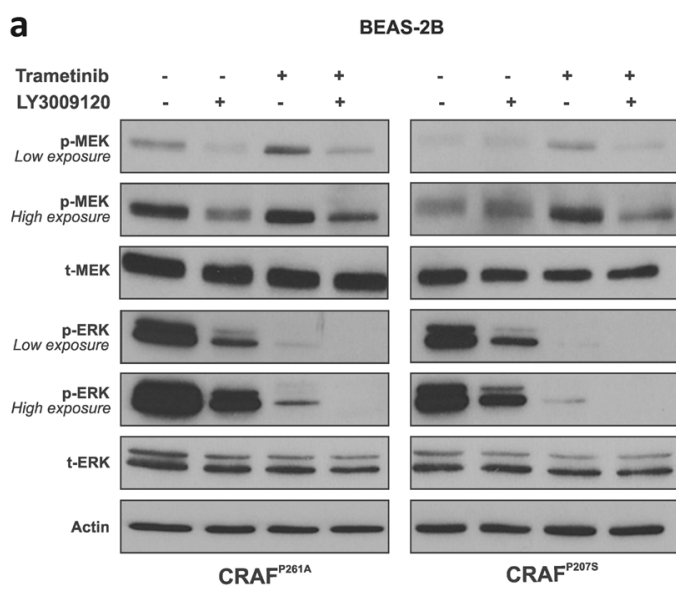

b

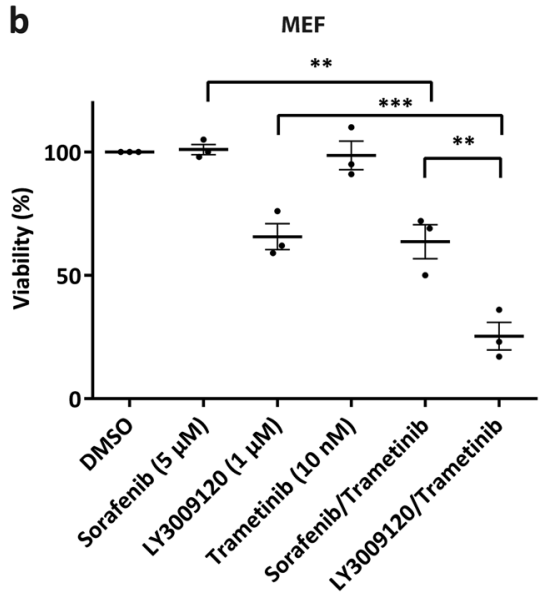

Fig. 4 CRAF $^{\mathrm{P} 261 \mathrm{~A}}$ predicts sensitivity to combination of LY3009120 and Trametinib. a BEAS-2B cells were transiently transfected with different CRAF expression vectors (wild type or mutant). Forty-eight hours post transfection, cells were treated for $2 \mathrm{~h}$ with DMSO, LY3009120 $(1 \mu \mathrm{M})$, and/or Trametinib $(25 \mathrm{nM})$, then lysed and subjected to western blotting analysis for the indicated proteins. b MEF cells stably expressing CRAF $^{\mathrm{P} 261 \mathrm{~A}}$ were treated with DMSO, Sorafenib, LY3009120, Trametinib, and the combinations of Sorafenib
$(5 \mu \mathrm{M})$ or LY3009120 $(1 \mu \mathrm{M})$ with Trametinib $(10 \mathrm{nM})$, for a duration of $72 \mathrm{~h}$. Cell viability was determined using CellTiter-Glo. The dots represent the means of the independent experiments, the horizontal lines with error bars represent the mean \pm SEM of three independent experiments each performed at least in triplicate. Statistical significance was indicated by $* *$ and $* * *$, which represent $p$-values $<$ 0.01 and 0.001 , respectively in corresponding p-ERK levels (Fig. 3a). This phenomenon was not observed in the presence of BRAF $^{\mathrm{WT}}$ (Supplementary Fig. S2). To further gain a broader insight into the link between the mode of RAF inhibition and the efficacy in suppressing $\mathrm{CRAF}^{\mathrm{P} 261 \mathrm{~A}}$-induced ERK activity, we also tested (Fig. 3b, c) the clinically available Type I RAF inhibitor Vemurafenib as well as the relatively weak but clinically available Type II RAF inhibitor Sorafenib [29] (multiple kinase inhibitor). As for Dabrafenib, Vemurafenib caused paradoxical ERK activation. Also, Sorafenib activated the ERK pathway rather than inhibiting it at $1 \mu \mathrm{M}$, the concentration used for the other inhibitors. However, one should notice that $1 \mu \mathrm{M}$ is a relatively low concentration for Sorafenib as the maximal plasma concentration of Sorafenib in patients reaches 10 to $21 \mu \mathrm{M}$ [40-42]. Previous reports confirm that Sorafenib causes ERK paradoxical activation at low doses [43-45]. However, at higher doses $(5 \mu \mathrm{M}$ and $10 \mu \mathrm{M}$ ), Sorafenib caused ERK inhibition (Fig. 3b). Overall, LY3009120 exerted the strongest ERK pathway inhibition (Fig. 3a, b and Supplementary Fig. S2). These results were consistent with our observations regarding the growth inhibitory effect of the tested RAF inhibitors in MEFs transduced with $\mathrm{CRAF}^{\mathrm{P} 261 \mathrm{~A}}$ (Fig. 3d).

\section{CRAF $^{\text {P261A }}$ predicts sensitivity to the combination of LY3009120 and Trametinib}

Combined MEK and BRAF targeting has shown superior efficacy in BRAF mutant cancers [18, 22, 23, 38, 39, 46-49]. We investigated whether similar effects are observed in the mutant CRAF context. MEK inhibitors are known to be ineffective or poorly effective in cells where ERK pathway activation is CRAF-mediated such as in mutant KRAS cells [50-52]. However, the MEK inhibitor Trametinib is known to be more efficient compared with several other MEK inhibitors in such cells [50]. As LY3009120 showed the highest ERK inhibitory effect among the RAF inhibitors we tested, we further studied the effect of Trametinib at the clinically relevant dose of $25 \mathrm{nM}$ as a single agent and in combination with LY3009120. Trametinib single agent treatment of lung epithelial BEAS-2B cells expressing CRAF mutants alone and together with $\mathrm{BRAF}^{\mathrm{WT}}$ led to increased MEK phosphorylation (Fig. 4a and Supplementary Fig. S3). However, increased MEK phosphorylation was not followed by increased ERK phosphorylation but by strong ERK inhibition. Other groups and we have previously described this phenomenon upon MEK inhibition in cells with CRAF-mediated ERK pathway activity [23, 50-53]. The ERK inhibitory effect of Trametinib alone was even stronger than for LY3009120 alone. Combination of LY3009120 and Trametinib led to an enhanced ERK inhibitory effect compared with single agent treatments, whether in the presence or absence of BRAF (Fig. 4a and Supplementary Fig. S3). Notably, the presence of LY3009120 decreased the Trametinib-induced MEK phosphorylation (Fig. 4a).

Finally, we tested the growth inhibitory effect of Trametinib $(10 \mathrm{nM})$ combined with LY3009120 (1 $\mu \mathrm{M})$ or combined with Sorafenib $(5 \mu \mathrm{M})$ in mouse embryonic fibroblasts expressing $\mathrm{CRAF}^{\mathrm{P} 261 \mathrm{~A}}$. In both cases, 
combinatorial treatments resulted in reduced cell viability compared with single agent treatments (Fig. 4b). Trametinib plus LY3009120 produced stronger growth inhibitory effects compared with Trametinib plus Sorafenib (Fig. 4b). Our findings predict sensitivity of cells with CRAF oncogene dependency to the combination of type II RAF and MEK inhibition.

In summary, two somatic CRAF mutations identified in a series of 41 NSCLC patients with a non-smoking history were examined for their ability to activate the MEK-ERK pathway and their therapeutic actionability with several pathway inhibitors. We show that one of these mutations $\left(\mathrm{CRAF}^{\mathrm{P} 261 \mathrm{~A}}\right)$ strongly activates the MEK-ERK pathway, whereas the other mutation $\left(\mathrm{CRAF}^{\mathrm{P} 207 \mathrm{~S}}\right)$ does not. The mode of RAF inhibition determines whether the ERK pathway will be suppressed or paradoxically activated in cells expressing the $\mathrm{CRAF}^{\mathrm{P} 261 \mathrm{~A}}$ mutation. Among the type II inhibitors tested, LY3009120 resulted in strongest ERK inhibitory effect. Moreover, combined LY3009120 and Trametinib (MEK inhibitor) treatment of cells expressing $\mathrm{CRAF}^{\mathrm{P} 261 \mathrm{~A}}$ even led to a stronger MEK and ERK inhibition. LY3009120 has shown promising preclinical efficacy in BRAF and KRAS mutant cells but the subsequent clinical trial (NCT02014116) exploring the efficacy of the inhibitor in melanoma, colon, NSCLC and pancreatic cancers led to poor pharmacodynamic responses in treated patients and discontinuation of the drug development $[29,54]$.

Regarding CRAF ${ }^{\mathrm{P} 207 \mathrm{~S}}$, our results show that this mutation does not activate the ERK pathway at higher levels compared with $\mathrm{CRAF}^{\mathrm{WT}}$ and does not transform the transduced cells. Further investigation is required to uncover whether $\mathrm{CRAF}^{\mathrm{P} 207 \mathrm{~S}}$ can deregulate other pathways and induce oncogenesis in co-operation with other protumorigenic events, or it is rather a passenger mutation. This study inspires discovery and characterization of CRAF mutations in lung and other cancers. Our results support the clinical exploration of the therapeutic exploitation of CRAF mutations in cancer [35].

Acknowledgements We deeply appreciate Professor Ilse Rooman's (LMMO-VUB) support to the present work. We thank Mathias VanBulck for his advice on EVOS microscopy usage and Professor Reuven Stein for providing our lab with the MEF cell lines. We thank Professor Karine Breckpot and Dr Cleo Goyvaerts (LMCT-VUB) for training and assistance for the use of lentiviral core facility. We thank Interfaculty Center Data processing \& Statistics (https://www.icds.be/) for the advice on statistical analyses.

Grant Support The work was funded by the Cancer Plan 29-39 Belgium and by the Wetenschappelijk Fonds Willy Gepts of the UZ Brussel; Noeparast A. was funded by an Interdisciplinary Research Program (IRP) Vrije Universiteit Brussel. Noor A. is the beneficiary of $\mathrm{Ph} . \mathrm{D}$. Fellowship from Vrije Universiteit Brussel and was funded by Armand Everaert. Giron P. and Eggermont C. are the beneficiaries of a Ph.D. Fellowship from the Research Foundation-Flanders (FWO) and
Emmanuel van der Schueren research scholarship by Kom op Tegen Kanker.

\section{Compliance with ethical standards}

Conflict of interest The authors declare that they have no conflict of interest.

Publisher's note: Springer Nature remains neutral with regard to jurisdictional claims in published maps and institutional affiliations.

Open Access This article is licensed under a Creative Commons Attribution 4.0 International License, which permits use, sharing, adaptation, distribution and reproduction in any medium or format, as long as you give appropriate credit to the original author(s) and the source, provide a link to the Creative Commons license, and indicate if changes were made. The images or other third party material in this article are included in the article's Creative Commons license, unless indicated otherwise in a credit line to the material. If material is not included in the article's Creative Commons license and your intended use is not permitted by statutory regulation or exceeds the permitted use, you will need to obtain permission directly from the copyright holder. To view a copy of this license, visit http://creativecommons. org/licenses/by/4.0/.

\section{References}

1. Lavoie H, Therrien M. Regulation of RAF protein kinases in ERK signalling. Nat Rev Mol Cell Biol. 2015;16:281-98.

2. Emuss V, Garnett M, Mason C, Marais R. Mutations of C-RAF are rare in human cancer because C-RAF has a low basal kinase activity compared with B-RAF. Cancer Res. 2005;65:9719.

3. Krauthammer M, Kong Y, Bacchiocchi A, Evans P, Pornputtapong $\mathrm{N}$, Wu $\mathrm{C}$, et al. Exome sequencing identifies recurrent mutations in NF1 and RASopathy genes in sun-exposed melanomas. Nat Genet. 2015;47:996-1002.

4. Tidyman WE, Rauen KA. The RASopathies: developmental syndromes of Ras/MAPK pathway dysregulation. Curr Opin Genet Dev. 2009;19:230-6.

5. Baik CS, Myall NJ, Wakelee HA. Targeting BRAF-mutant nonsmall cell lung cancer: from molecular profiling to rationally designed therapy. Oncologist. 2017;22:786-96.

6. Imielinski M, Greulich H, Kaplan B, Araujo L, Amann J, Horn L, et al. Oncogenic and sorafenib-sensitive ARAF mutations in lung adenocarcinoma. J Clin Invest. 2014;124:1582-6.

7. Molzan M, Schumacher B, Ottmann C, Baljuls A, Polzien L, Weyand $\mathrm{M}$, et al. Impaired binding of $14-3-3$ to $\mathrm{C}-\mathrm{RAF}$ in Noonan syndrome suggests new approaches in diseases with increased Ras signaling. Mol Cell Biol. 2010;30:4698-711.

8. Molzan M, Ottmann C. Synergistic binding of the phosphorylated S233- and S259-binding sites of C-RAF to one 14-3-3zeta dimer. J Mol Biol. 2012;423:486-95.

9. Nussinov R, Zhang M, Tsai C-J, Liao T-J, Fushman D, Jang H. Autoinhibition in Ras effectors Raf, PI3Kalpha, and RASSF5: a comprehensive review underscoring the challenges in pharmacological intervention. Biophys Rev. 2018;10:1263-82.

10. Dhillon AS, Meikle S, Yazici Z, Eulitz M, Kolch W. Regulation of Raf-1 activation and signalling by dephosphorylation. EMBO J. 2002;21:64-71.

11. Thorson JA, Yu LW, Hsu AL, Shih NY, Graves PR, Tanner JW, et al. 14-3-3 proteins are required for maintenance of Raf-1 phosphorylation and kinase activity. Mol Cell Biol. 1998;18:5229-38.

12. Atefi M, Titz B, Tsoi J, Avramis E, Le A, Ng C, et al. CRAF $\mathrm{R} 391 \mathrm{~W}$ is a melanoma driver oncogene. Sci Rep. 2016;6:27454. 
13. Antony R, Emery CM, Sawyer AM, Garraway LA. CRAFmutations confer resistance to RAF inhibitors. Cancer Res. 2013;73:4840-51.

14. King AJ, Sun H, Diaz B, Barnard D, Miao W, Bagrodia S, et al. The protein kinase Pak3 positively regulates Raf-1 activity through phosphorylation of serine 338. Nature. 1998;396:180-3.

15. Mason CS, Springer CJ, Cooper RG, Superti-Furga G, Marshall CJ, Marais R. Serine and tyrosine phosphorylations cooperate in Raf-1, but not B-Raf activation. EMBO J. 1999;18:2137-48.

16. Zang M, Gong J, Luo L, Zhou J, Xiang X, Huang W, et al. Characterization of Ser338 phosphorylation for Raf-1 activation. J Biol Chem. 2008;283:31429-37.

17. Kubicek M, Pacher M, Abraham D, Podar K, Eulitz M, Baccarini M. Dephosphorylation of Ser-259 regulates Raf-1 membrane association. J Biol Chem. 2002;277:7913-9.

18. Whittaker SR, Cowley GS, Wagner S, Luo F, Root DE, Garraway LA. Combined pan-RAF and MEK inhibition overcomes multiple resistance mechanisms to selective RAF inhibitors. Mol Cancer Ther. 2015;14:2700-11.

19. Rosell R, Karachaliou N. BRAF(V600E) and BRAF-inactivating mutations in NSCLC. Lancet Oncol. 2017;18:1286-7.

20. Yao Z, Torres NM, Tao A, Gao Y, Luo L, Li Q, et al. BRAF mutants evade ERK-dependent feedback by different mechanisms that determine their sensitivity to pharmacologic inhibition. Cancer Cell. 2015;28:370-83.

21. Zhang C, Spevak W, Zhang Y, Burton EA, Ma Y, Habets G, et al. RAF inhibitors that evade paradoxical MAPK pathway activation. Nature. 2015;526:583-6.

22. Noeparast A, Teugels E, Giron P, Verschelden G, De Brakeleer S, Decoster L, et al. Non-V600 BRAF mutations recurrently found in lung cancer predict sensitivity to the combination of Trametinib and Dabrafenib. Oncotarget. 2017;8:60094-108.

23. Noeparast A, Giron P, De Brakeleer S, Eggermont C, De Ridder U, Teugels E, et al. Type II RAF inhibitor causes superior ERK pathway suppression compared to type I RAF inhibitor in cells expressing different BRAF mutant types recurrently found in lung cancer. Oncotarget. 2018;9:16110-23.

24. Dankner M, Rose AAN, Rajkumar S, Siegel PM, Watson IR. Classifying BRAF alterations in cancer: new rational therapeutic strategies for actionable mutations. Oncogene. 2018;37:3183-99.

25. Hatzivassiliou G, Song K, Yen I, Brandhuber BJ, Anderson DJ, Alvarado R, et al. RAF inhibitors prime wild-type RAF to activate the MAPK pathway and enhance growth. Nature. 2010;464:431-5.

26. Holderfield M, Nagel TE, Stuart DD. Mechanism and consequences of RAF kinase activation by small-molecule inhibitors. Br J Cancer. 2014;111:640-5.

27. Karoulia Z, Gavathiotis E, Poulikakos PI. New perspectives for targeting RAF kinase in human cancer. Nat Rev Cancer. 2017;17:676-91

28. Molnar E, Rittler D, Baranyi M, Grusch M, Berger W, Dome B, et al. Pan-RAF and MEK vertical inhibition enhances therapeutic response in non-V600 BRAF mutant cells. 2018;18:542.

29. Peng S-B, Henry J, Kaufman M, Lu W-P, Smith B, Vogeti S, et al. Inhibition of RAF isoforms and active dimers by LY3009120 leads to anti-tumor activities in RAS or BRAF mutant cancers. Cancer Cell. 2015;28:384-98.

30. Poulikakos PI, Zhang C, Bollag G, Shokat KM, Rosen N. RAF inhibitors transactivate RAF dimers and ERK signalling in cells with wild-type BRAF. Nature. 2010;464:427-30.

31. Rajakulendran T, Sahmi M, Lefrancois M, Sicheri F, Therrien M. A dimerization-dependent mechanism drives RAF catalytic activation. Nature. 2009;461:542-5.

32. Hu J, Stites EC, Yu H, Germino EA, Meharena HS, Stork PJ, et al. Allosteric activation of functionally asymmetric RAF kinase dimers. Cell. 2013;154:1036-46.
33. Röring M, Herr R, Fiala GJ, Heilmann K, Braun S, Eisenhardt $\mathrm{AE}$, et al. Distinct requirement for an intact dimer interface in wild-type, V600E and kinase-dead B-Raf signalling. EMBO J. 2012;31:2629-47.

34. TODARO GJ, GREEN H. Quantitative studies of the growth of mouse embryo cells in culture and their development into established lines. J Cell Biol. 1963;17:299-313.

35. Shapira S, Barkan B, Friedman E, Kloog Y, Stein R. The tumor suppressor neurofibromin confers sensitivity to apoptosis by Rasdependent and Ras-independent pathways. Cell Death Differ. 2007; 14:895-906

36. Wan PTC, Garnett MJ, Roe SM, Lee S, Niculescu-Duvaz D, Good VM, et al. Mechanism of activation of the RAF-ERK signaling pathway by oncogenic mutations of B-RAF. Cell. 2004;116:855-67.

37. Dumaz N, Hayward R, Martin J, Ogilvie L, Hedley D, Curtin JA, et al. In melanoma, RAS mutations are accompanied by switching signaling from BRAF to CRAF and disrupted cyclic AMP signaling. Cancer Res. 2006;66:9483 LP-9491.

38. Greger JG, Eastman SD, Zhang V, Bleam MR, Hughes AM, Smitheman KN, et al. Combinations of BRAF, MEK, and PI3K/ mTOR inhibitors overcome acquired resistance to the BRAF inhibitor GSK2118436 dabrafenib, mediated by NRAS or MEK mutations. Mol Cancer Ther. 2012;11:909-20.

39. King AJ, Arnone MR, Bleam MR, Moss KG, Yang J, Fedorowicz $\mathrm{KE}$, et al. Dabrafenib; preclinical characterization, increased efficacy when combined with trametinib, while BRAF/MEK tool combination reduced skin lesions. PLoS ONE. 2013;8:e67583.

40. Li L, Zhao M, Navid F, Pratz K, Smith BD, Rudek MA, et al. Quantitation of sorafenib and its active metabolite sorafenib Noxide in human plasma by liquid chromatography-tandem mass spectrometry. J Chromatogr B Anal Technol Biomed Life Sci. 2010;878:3033-8

41. Takezawa K, Okamoto I, Yonesaka K, Hatashita E, Yamada Y, Fukuoka M. et al. Sorafenib inhibits non-small cell lung cancer cell growth by targeting B-RAF in KRAS wild-type cells and CRAF in KRAS mutant cells. Cancer Res. 2009;69:6515-21.

42. Dierks C, Pfeifer D, Jumaa H, Veelken H, Brummer T, Zirlik K. Combination of kinase inhibitors overcomes B-Raf inhibitorinduced paradoxical ERK activation in CLL cells in vitro potential implications for CLL treatment. Blood. 2013;122:4121 LP-4121.

43. Arnault J-P, Mateus C, Escudier B, Tomasic G, Wechsler J, Hollville E, et al. Skin tumors induced by sorafenib; paradoxical RAS-RAF pathway activation and oncogenic mutations of HRAS, TP53 and TGFBR1. Clin Cancer Res. 2011;18:263-72.

44. Chen Y, Liu Y-C, Sung Y-C, Ramjiawan RR, Lin T-T, Chang C$\mathrm{C}$, et al. Overcoming sorafenib evasion in hepatocellular carcinoma using CXCR4-targeted nanoparticles to co-deliver MEKinhibitors. Sci Rep. 2017;7:44123.

45. Fouladi F, Jehn LB, Metzelder SK, Hub F, Henkenius K, Burchert A, et al. Sorafenib induces paradoxical phosphorylation of the extracellular signal-regulated kinase pathway in acute myeloid leukemia cells lacking FLT3-ITD mutation. Leuk Lymph. 2015;56:2690-8.

46. Johnson DB, Flaherty KT, Weber JS, Infante JR, Kim KB, Kefford RF, et al. Combined BRAF (Dabrafenib) and MEK inhibition (Trametinib) in patients with BRAFV600-mutant melanoma experiencing progression with single-agent BRAF inhibitor. J Clin Oncol. 2014;32:3697-704.

47. Corcoran RB, Atreya CE, Falchook GS, Kwak EL, Ryan DP, Bendell JC, et al. Combined BRAF and MEK inhibition with dabrafenib and trametinib in BRAF V600-mutant colorectal cancer. J Clin Oncol. 2015;33:4023-31.

48. Long GV, Flaherty KT, Stroyakovskiy D, Gogas H, Levchenko E, de Braud F, et al. Dabrafenib plus trametinib versus dabrafenib 
monotherapy in patients with metastatic BRAF V600E/K-mutant melanoma: long-term survival and safety analysis of a phase 3 study. Ann Oncol J Eur Soc Med Oncol. 2017;28:1631-9.

49. Planchard D, Besse B, Groen HJM, Souquet P-J, Quoix E, Baik $\mathrm{CS}$, et al. Dabrafenib plus trametinib in patients with previously treated BRAF(V600E)-mutant metastatic non-small cell lung cancer: an open-label, multicentre phase 2 trial. Lancet Oncol. 2016;17:984-93.

50. Lito P, Saborowski A, Yue J, Solomon M, Joseph E, Gadal S, et al. Disruption of CRAF-mediated MEK activation is required for effective MEK inhibition in KRAS mutant tumors. Cancer Cell. 2014;25:697-710.

51. Hatzivassiliou G, Haling JR, Chen H, Song K, Price S, Heald R, et al. Mechanism of MEK inhibition determines efficacy in mutant KRAS- versus BRAF-driven cancers. Nature. 2013;501:232-6.
52. Lamba S, Russo M, Sun C, Lazzari L, Cancelliere C, Grernrum $\mathrm{W}$, et al. RAF suppression synergizes with MEK inhibition in KRAS mutant cancer cells. Cell Rep. 2014;8:1475-83.

53. Gilmartin AG, Bleam MR, Groy A, Moss KG, Minthorn EA, Kulkarni SG, et al. GSK1120212 (JTP-74057) is an inhibitor of MEK activity and activation with favorable pharmacokinetic properties for sustained in vivo pathway inhibition. Clin Cancer Res. 2011;17:989-1000.

54. Vakana E, Pratt S, Blosser W, Dowless M, Simpson N, Yuan XJ, et al. LY3009120, a panRAF inhibitor, has significant anti-tumor activity in BRAF and KRAS mutant preclinical models of colorectal cancer. Oncotarget. 2017;8:9251-66.

55. Geissmann Q. OpenCFU, a new free and open-source software to count cell colonies and other circular objects. PLoS ONE. 2013;8: e54072. 